\title{
An Empirical Study on the Teaching Reform of Sports Statistics Based on PBL Teaching Method
}

Jianwei He

College of Physical Education of Guangzhou University, Guangzhou, Guangdong Province, 510006, China.

Project: 1. Natural Science Foundation project of Fujian Provincial Department of Science and Technology: Research on Th1/Th2 imbalance mechanism of Far-infrared ceramic microbeads by T-bet /GATA3 regulation; Project No. : 2016J01404;

2. Science and Technology Service Project of General Administration of Sport of China: Project name: Far-infrared ceramic microbeads provide service guarantee for national archers' muscle injury and fatigue recovery; Project No. : 2017HT008

3. Research Launch Project of Introducing Talents to Guangzhou University -- High-level University Construction project of Guangzhou University -- Teacher team Construction Project: Project No. : 2900603999-290060344

Abstract: As far as the current development of undergraduate education in my country is concerned, the physical education major has become one of the important components of its professional composition, which affects the comprehensiveness of teaching to a certain extent. Therefore, when the relevant colleges and universities reform the teaching system of the physical education major, they should conduct in-depth exploration of their specific teaching courses in a timely manner, so as to realize the teaching progress in the new era in a comprehensive and detailed manner. Sports statistics, as one of the key components of the physical education major, reforms and empirical research on its teaching in a timely manner is of constructive significance for promoting its comprehensive development strength. Keywords: PBL teaching method; Sports statistics; Teaching Reform; Empirical Research

With the continuous development and progress of the economy and society, the demand for talents in all walks of life in society has gradually increased, and the corresponding requirements have also increased. While this has promoted the innovation and progress of a series of educational and teaching activities in the new era, it has also increased the pressure on educators. Therefore, in the context of innovative social development, relevant educators consciously reform their own series of educational and teaching activities to adapt to the development needs of actual educational work to the greatest extent, so as to help students master professional learning knowledge. At the same time, it exercises its own innovation ability and adaptability, laying a certain foundation for its future development. The PBL teaching method is a new type of teaching method that conforms to the current society. There are differences in education and teaching concepts, actual implementation methods, teaching evaluation and evaluation systems, and final teaching effects. It has certain adaptability and promotion in the new era. It is helpful for students to better accept and understand specific teaching knowledge.

\section{The connotation of PBL teaching method}

PBL teaching method is a new type of teaching mode that conforms to the modern new curriculum reform teaching method, which can be interpreted as a problem-based learning method. The PBL teaching method originated from medical education. It is based on the setting of learning situations to guide students to think and learn, so that students

Copyright (C) 2020 Jianwei He

doi: 10.18282/le.v9i5.1250

This is an open-access article distributed under the terms of the Creative Commons Attribution Non-Commercial License

(http://creativecommons.org/licenses/by-nc/4.0/), which permits unrestricted non-commercial use, distribution, and reproduction in any medium, provided the original work is properly cited. 
can consciously stimulate their own learning enthusiasm and improve subjective learning while correctly understanding their own learning subject status. initiative. Compared with the traditional teaching mode, PBL teaching method is more flexible. It is to plan and carry out various educational and guiding activities based on students as the center to help deepen their knowledge learning and understanding and gradually build their own unique knowledge Architecture structure. Therefore, when relevant teaching management units actually apply the PBL teaching method, they should first objectively and comprehensively analyze the current situation of their own education and teaching, carefully judge the appropriate entry point of the PBL teaching method, and then analyze the characteristics of the method in a timely manner to effectively show Its practical role. As far as the practical application of PBL teaching method is concerned, it has the characteristics of problem-driven, student-oriented teaching core, teacher-student collaborative learning, practical learning, and knowledge application to project products. When the relevant teaching management personnel introduce the PBL teaching method, they should guide students to learn knowledge with specific questions, help them answer questions to improve their knowledge learning level, and achieve a comprehensive grasp of scientific and cultural knowledge. In addition, under the guidance of the teaching methods of the middle school, students can gradually cultivate their learning enthusiasm and initiative, effectively stimulate their own learning potential, and cultivate their good knowledge application ability.

\section{Status Quo of the Development of Sports Statistics Teaching}

Sports statistics is one of the basic courses for sports majors. The establishment of this course is of great significance to the improvement of the comprehensive quality of sports majors. However, as far as the actual teaching development is concerned, most teachers fail to grasp the fundamental purpose of professional curriculum teaching correctly, and fail to effectively teach and cultivate their knowledge and ability according to the training requirements of sports professionals, resulting in poor actual learning effects. good. In traditional sports statistics teaching courses, most teachers focus on the orderly development of classroom teaching activities, and use their own teaching rhythm as the direction to show students knowledge points such as calculations, reasoning, and principle verification. The actual learning and knowledge reception situation, if things go on like this, will make the students' learning trajectory and the teacher's teaching trajectory inconsistent, hindering the efficient progress of subsequent teaching courses. Moreover, it is difficult to learn the principles of sports statistics. Teachers are required to explain in the classroom by introducing actual cases to intuitively show students the practical application of the knowledge of sports statistics. For students' learning, case teaching can not only help them to develop their thinking in a targeted manner, but also help them implement the learning of various principles and content, and lay a solid foundation for their subsequent high-level knowledge points. With the continuous development and progress of science and technology, the universality of the use of computers has gradually increased. Sports statistics teachers have also begun to try to introduce computers as teaching aids into the classroom. On the one hand, they can appropriately alleviate students' learning pressure, and on the other hand, they can also help deepen Knowledge education level, to help students complete new knowledge learning tasks with quality and quantity. For example, the emergence of statistical analysis-related applications such as Excel, SPAA, and SAS are all important manifestations of the organic combination of modern technology and statistics, which require students to understand and master. However, while the teaching conditions of sports statistics are improving, teachers have not solved the problem of separating "teaching" and "learning" in a timely manner. Even because of the emergence of convenient learning factors, they have created a way for students to be lazy and make them understand the principles. Problems such as insufficient depth, misuse and misuse of statistics hinder the sustainable development and progress of the teaching process of sports statistics.

\section{Sports Statistics Teaching Reform Based on PBL Teaching Method}

\subsection{Set up teaching goals scientifically and reasonably}

The diversity of current social development is gradually increasing, and there are many information data in all walks of life. This has caused increased pressure on statistical work while also bringing new opportunities for its future development. Because in today's society, data statistics are inseparable from real life work. It can bring valuable information for work and study, and has gradually developed into one of the necessary skills for modern high-quality and high-level talents. For physical education students, the significance of the sports statistics course is not only to 
cultivate their information acquisition ability, but also to exercise their divergent thinking, develop a good habit of indepth inquiry and study, and improve their own communication through scientific research. Level of knowledge and comprehensive development quality to enhance their comprehensiveness. Therefore, when setting teaching goals for sports statistics courses, physical education teachers should rationally refine them according to the professional learning requirements and the current development of students, so as to help students build a knowledge learning system based on the Able to gain a sense of accomplishment after completing a learning task, and effectively mobilize their interest in learning. For most sports majors, the fundamental purpose of sports statistics course learning is to improve their own comprehensive quality development level, master the operation of various application software programs, and lay a solid foundation for their subsequent data analysis capabilities. Those students who are interested in carrying out indepth statistical research work should add diversified statistical analysis learning content in a timely manner based on the general learning objectives, master more statistical analysis methods, and be able to deal with various complex problems in an orderly manner. This helps their learning level to improve in an orderly manner.

\subsection{Optimize teaching content}

A comprehensive and efficient grasp of teaching content is the fundamental purpose of students participating in classroom learning activities. Therefore, when teachers introduce and apply the PBL teaching method, they can incorporate their teaching concepts into the division of teaching content, and use the problem as a guide to help students distinguish the priority of knowledge learning content and understand it. In addition, through the application of this teaching method, students can also intuitively feel the practical application of knowledge, which is conducive to the orderly development of their follow-up knowledge application ability learning activities. Therefore, when teachers use PBL teaching method to teach students the knowledge of sports statistics, they can reform and optimize their specific teaching content in a timely manner, and realize the simultaneous update of teaching mode and knowledge.

\subsection{Restructure the curriculum}

The curriculum structure is organically linked by the various teaching parts. It is an important supporting framework for the curriculum system and a fundamental factor that helps teachers to carry out a series of teaching activities in an orderly manner. Especially for physical education students, most of them are liberal arts students with poor logical thinking ability. Therefore, in accordance with the requirements of the PBL teaching method, teachers rationally reconstruct the curriculum structure and measure the proportion between required and optional courses, so as to adapt to the learning characteristics of contemporary college students to the greatest extent, and also help them recognize each learning goal. In order to guide them to participate in actual learning activities in an orderly manner.

\section{Concluding remarks}

To sum up, the teaching of sports statistics is one of the difficult problems for students majoring in sports, and the introduction of PBL teaching method is to adapt to the characteristics of modern university teaching, help teachers reduce teaching tasks and guide students to be targeted Carry out professional knowledge system learning activities to promote their comprehensive learning capabilities. Moreover, under the guidance of new teaching methods, students can cultivate their own knowledge application ability in an all-round way, laying a solid foundation for future work needs.

\section{References}

1. Dong Yanyan. Empirical research on the teaching reform of sports statistics based on PBL teaching method [J]. Journal of Henan College of Finance and Taxation, 2019, 33(04): 75-78.

2. Liu Chao, Li Tengjiao, Wei Qiang. Research on the Cultivation of Innovative and Entrepreneurial Talents Led by Multidimensional Collaborative Platform Projects__Exploration Based on the Application Perspective of PBL Teaching Method [J]. Journal of Hebei Software Vocational and Technical College, 2020, 22(02) ): 34-38.

3. You Yonghao. The online and offline hybrid flipped classroom teaching reform of sports statistics guided by the OBE concept[J]. Journal of Luoyang Normal University, 2020, 39(05): 49-51. 